\title{
Collisions of highly charged ions with electrons, atoms and
}

\section{surfaces}

C. C. Havener, M. E. Bannister, L. Folkerts, J. W. Hale, M. Pieksma, J. Shinpaugh ${ }^{\star}$, and

F. W. Meyer

Oak Ridge National Laboratory, Oak Ridge, Tennessee 37831-6372

(September 30, 1994)

At the Oak Ridge Multicharged Ion Source Facility, an experimental atomic collisions physics program is centered around a recently upgraded Electron Cyclotron Resonance (ECR) multicharged ion source. The $10 \mathrm{GHz}$ CAPRICE source has been in operation since October 22, 1992, and has provided more intense, higher charge ion beams than our previous ECR ion source. Intense metallic beams have recently become available with the installation of a metallic oven on the source. In addition to measurements of electron-impact excitation, carried out in collaboration with the Joint Institute for Laboratory Astrophysics (JILA), experiments are presently on-line to study electron-impact ionization, low-energy ion-atom collisions, and ionsurface interactions. A brief summary of our various activities with an emphasis on the new capabilities is presented.

\section{MASTER}

\footnotetext{
The submitted manuscript has been authored by a contracror of the U.S. Government under coniract DE-ACO5-84OR21400. Accortin the U.S. Government retains a nonexclusive, royairy-free lict oublhk of reproduce the published form of this contrinition, Nlow abers to do șó, for U.S. Government purposes."
} 


\section{DISCLAIMER}

Portions of this document may be illegible in electronic image products. Images are produced from the best available original document. 


\section{ECR MULTICHARGED ION RESEARCH FACILITY}

An experimental atomic collision physics program at Oak Ridge National Laboratory (ORNL) is centered around a $10 \mathrm{GHz}$ Caprice ECR multicharged ion source. This source has been in operation since October 22, 1992, and has replaced the previous ECR source [1] built at ORNL in 1983, providing more intense and stable beams. To illustrate the improvement in total source output, for Ar ions the new ECR source has produced up to $20 \mu \mathrm{A}$ of $\mathrm{Ar}^{12+}$ at a source potential of $17 \mathrm{kV}$, a factor of 30 improvement over what was obtained with the old source, and up to about $1 \mathrm{nA}$ of $\mathrm{Ar}^{17+}$, a factor of $10^{5}$ increase over the corresponding previous ECR output. A similar improvement is observed for second-row elements; for example, the new ECR source has produced $2.5 \mu \mathrm{A}$ of ${ }^{15} \mathrm{~N}^{7+}$, which is to be compared to $0.1 \mu \mathrm{A}$ obtained with the old source. For ion beams of lower charge states, source output improvements of factors of 3-5 are more typical.

Improvements in usable beam intensity can be illustrated with the performance of the ion-atom merged-beams apparatus, whose beam acceptance is the lowest of all the experiments now on line. Results show a significant improvement in beam profile together with a minimum factor of $2-3$ increase in beam intensity over that attainable with the old ECR source. Throughput tests with $\mathrm{N}^{7+}$ indicate that, with the new ECR source, merged-beams cross-section measurements will now be possible with a fully stripped ion.

Also, metal ion production capability has recently been developed for the new ECR source by implementation of a minature oven incorporated into the end of the central electrode of the coax microwave injection waveguide, located immediately adjacent to the ECR source main plasma stage. Multicharged ions of refractory as well as lower melting point metallic species have been produced by use of volatile metal-oxide and -chloride powders which have sufficient vapor pressures for ion beam production even at moderate oven temperatures (i.e., 600-700 C). Using this technique, stable Mo beams in charge states up to + 16 have been produced, with source charge lifetimes approaching 40 hours. For lower melting point metals, the oven has been used to generate vapor directly from the pure metal. In 
this mode, lead ion beams in charge states up to +36 have been produced, which were used in recent surface scattering measurments, as described in this manuscript.

\section{ELECTRON-IMPACT IONIZATION OF MULTICHARGED IONS}

An electron crossed beams apparatus [2] has been used to measure absolute cross sections for electron impact ionization of multicharged ions. A summary of measurements (19851992) using the old ECR source can be found in an ORNL Report [3]. An extensive list of some eighty target ions, ranging from $Z=5$ (boron) to $Z=92$ (uranium) in charge states from +1 to +16 have been investigated at ORNL with this crossed-beam apparatus. The recently modified apparatus [4] has made it possible to perform measurements at electron collision energies in the range 30 to $2000 \mathrm{eV}$ with an energy resolution as low as $0.5 \mathrm{eV}$.

This improved apparatus has been used to measure [4] electron impact ionization cross sections for $\mathrm{Kr}^{4+}, \mathrm{Kr}^{5+}$, and $\mathrm{Kr}^{7+}$ ions, which are of interest in the interpretation of the $\mathrm{Kr}$ beam diagnostic used on various fusion plasma devices. The measured cross sections are in good agreement with distorted-wave calculations and show significant contributions from excitation-autoionization. Non-zero cross sections below threshold measured for the +4 and $+5 \mathrm{Kr}$ charge states indicate significant metastable components for these two beams.

Cross section measurments are in progress for electron-impact ionization of $\mathrm{Mo}^{4+}$ and $\mathrm{Mo}^{5+}$ ions using the newly developed metallic ion beam capability of the ECR ion source. The cross sections for $\mathrm{Mo}^{5+}$ ionization are measured in the $30-500 \mathrm{eV}$ range with an absolute uncertainty of about $9 \%$ near the peak value of the cross section $\left(42 \times 10^{-18} \mathrm{~cm}^{2}\right.$ at 120 eV.) The measurements are in good agreement with configuration-average distorted-wave (CADW) calculations of Pindzola et al. The measured cross sections indicate that indirect processes such as excitation-autoionization dominate direct ionization by a 5.7 ratio near the peak of the cross section. The $\mathrm{Mo}^{5+}$ ion beam was found to contain about $3 \%$ metastable ions, likely in the $4 \mathrm{p}^{5} 4 \mathrm{~d}^{2}{ }^{4} F$ state. Preliminary results of the ionization cross section mea- 
surments for $\mathrm{Mo}^{4+}$ (see Figure I) show that the cross section peaks at $73 \times 10^{-18}$ near 100 $\mathrm{eV}$. Similar to the case for $\mathrm{Mo}^{5+}$ ionization, indirect processes contribute up to four times the cross section that direct ionization does near the peak and the measured cross sections show good agreement with CADW calculations.

\section{ELECTRON-IMPACT EXCITATION OF MULTICHARGED IONS}

An electron-merged beams apparatus (see Ref. [5]) has been developed by JILA in collaboration with ORNL to measure absolute cross sections for electron impact excitation of multicharged ions. The unique merged-beams configuration makes it possible to separate inelastically scattered electrons travelling forward and backward in the laboratory frame, and hence to infer gross features of the electron angular scattering in the center-or-mass (CM) frame. Recent absolute measurements [6] for the $3 \mathrm{~s} 3 \mathrm{p}$ excitation of $\mathrm{Na}$-like $\mathrm{Ar}^{7+}$ found 90 $\%$ of the inelastically scattered electrons to be ejected into the backward quadrant in the CM frame. This experimental observation of backscattering was confirmed recently [7] by close-coupling, distorted-wave, and classical-trajectory Monte Carlo calculations. Absolute cross section measurements [5] for the $2 \mathrm{~s} \rightarrow 2 \mathrm{p}$ excitation of Li-like $\mathrm{O}^{5+}$ show a non-zero cross secton below the excitation threshold, the energy dependence of which suggests the presence of short-lived metastable components in the incident beam, with a lifetime of 0.9 $\mu \mathrm{s}$. Theoretical efforts are currently underway to identify such a metastable component in the $\mathrm{O}^{5+}$ system. The measured cross sections above threshold are in good agreement with a seven-state close coupling calculation. Both quantum-mechanical and semi-classical calculations for this system show more than $90 \%$ of the electrons causing excitation to be ejected in the backward direction in the CM frame.

Recently, absolute cross section measurements [8] were made of the near threshold excitation of the $4 \mathrm{~s}^{2}{ }^{1} S \rightarrow 4 s 4 p^{3} \mathrm{P}$ intercombination transition in $\mathrm{Kr}^{6+}$ The cross section was found to be dominated by resonance structures (see Figure II), ascribed to dielectronic capture followed by autoionization, and is the first observation of resonances in the excitation 
of a multicharged ion. The measured cross section will serve as a benchmark for theoretical calculations currently underway whose goal is the identification of the doubly excited states responsible for the observed structure. The next measurements to be undertaken will investigate the dielectronic resonance structure predicted theoretically for near-threshold excitation of $\mathrm{Ar}^{6+}$.

\section{ION-SURFACE INTERACTIONS}

The neutralization and relaxation processes of multicharged ions interacting with a metal surface are being investigated. Measurements [9] have been made of scattered projectile angular and charge state distributions for $3.75 \mathrm{keV} / \mathrm{u} \mathrm{O}^{q+}(3 \leq q \leq 8)$ and $1.2 \mathrm{keV} / \mathrm{u} \mathrm{Ar}^{q+}$ ( $3 \leq 14)$ grazingly incident on a $\mathrm{Au}(110)$ single crystal target. The experiment utilized a recently installed two dimensional position sensitive detector in conjunction with a well collimated incident multicharged ion beam. For beams incident along low index target azimuthal directions, the characteristic "banana-shaped" angular distributions of the scattered projectiles were observed that are indicative of surface channeling (see Figure III). Charge state distributions were obtained by electrostatic analysis of a narrow slice of the scattered

ions selected by a set of moveable slits downstream of the crystal target. Calculations of the projectile scattering from a simulated $\mathrm{Au}(110)$ lattice closely reproduce the observed angular distributions (see Figure III), and indicate that the projectiles spend less than 30 femtoseconds within $2 \mathrm{~A}^{0}$ of the $\mathrm{Au}$ surface, and have a maximum surface penetration depth of less than $1 \mathrm{~A}^{0}$. Nevertheless, for incident $\mathrm{O}^{q+}$ ions, almost complete charge equilibration is observed in the scattered projectile charge state distributions. The above observations, together with modelling calculations of the ion trajectories, suggest that already at the target interface, the projectile neutralization rates are faster than $10^{15} \mathrm{~s}^{-1}$, and that strong screening effects are present as well, which facilitate electron capture directly to the $\mathrm{L}$ and $\mathrm{M}$ shells of the oxygen projectile.

Using the recently developed metal ion production capability of the new ECR multi- 
charged ion source, measurements have been made of the angular scattering distributions for $150-300 \mathrm{keV} \mathrm{Pb}^{q+}(11 \leq \mathrm{q} \leq 36)$ and $\mathrm{I}^{q+}(10 \leq \mathrm{q} \leq 25)$ ions grazingly incident on $\mathrm{Au}(110)$. The motivation behind these measurements was to determine the perpendicular projectile energy gain due to image charge acceleration prior to surface impact in a range of charge states overlapping earlier measurments by Winter et al. [10] using $\mathrm{Xe}^{q+}$ ions, also under grazing incidence conditions. These earlier measurements showed some evidence of deviation from the $\mathrm{q}^{3 / 2}$ charge state dependence [11] expected under the assumption of step-wise neutralization above the surface. For charge states up to +29 the inferred projectile energy gains were found to have the expected q dependence. Furthermore, in the region of charge state overlap, the energy gains inferred for the $\mathrm{I}^{q+}$ and $\mathrm{Pb}^{q+}$ ions were, within the experimental uncertainty, the same. For charge states +30 and higher, however, the determined

energy gains fell systematically below the expected $\mathrm{q}^{3 / 2}$ trend, just as had been observed by Winter et al. In view of the different ionic species used, this effect is not likely to result from the projectile atomic structure. Energy gains inferred from studies of the saturation of potential electron emission induced by normally incident ions of charge up to +72 show no evidence [12] of such deviation, and suggest that the presence of the relatively large parallel velocity components in the case of the grazing geometry measurments may have more significant implications for the above-surface neutralization of multicharged ions than previously thought.

\section{LOW-ENERGY ION-ATOM COLLISIONS}

An ion-atom merged-beams apparatus [13] is used to measure absolute cross sections for total electron capture for collision with multicharged ions and $\mathrm{H}$ (or D) in ground and excited states in the energy range between 0.1 and $5000 \mathrm{eV} / \mathrm{u}$. At the higher energies the behavior of total cross sections has been successfully parameterized in terms of ionic charge, target binding energy, and collision energy. However, at these higher energies, charge transfer to 
specific states is electron-core dependent and has been investigated by both photon-emission and translation-energy spectroscopy. At the lower energies cross sections measurements are not extensive and even total cross sections are known to be affected by the ionic core. Fully quantal molecular state calculatioins which are generally assumed to be the most accurate at the lower energies, are difficult to perform, often are sensitive to fine details in the method, and have only been tested on a few systems.

Advantages of using the merged-beams technique are that the measurements are absolute, there is a large angular collection in the center-of-mass frame, and that the apparatus is able to access almost five orders of magnitude in collision energies. Recent ion-atom mergedbeams measurements of $\mathrm{C}^{3+}+\mathrm{H}$ (D) [14] support a recent state-of-the-art 22-state molecular orbital calculation by L. F. Errea et. al. [15], which suggests a need to renormalize previous state-selective measurements at the higher collision energies. For $\mathrm{N}^{4+}$ collisions, an analysis of both the low energy behavior and strong structure in the measured and predicted total cross sections has been performed in collaboration with M. Kimura of Argonne National Laboratory. It was found that small differences in the quality of the calculated molecular states and the neglect of electron translational factors can lead to large differences in the low energy behavior of the predicted cross section. Recent remeasurement of this system (see Figure IV) confirms our previous results [16] and resolves the discrepancy between the two recent calculations $[17,18]$ whose predictions differ by an order of magnitude at 0.1 $\mathrm{eV} / \mathrm{u}$. Preliminary measurements have been performed on heavier ions, for these collision systems detailed calculations do not exist. Preliminary measurements for $\mathrm{Cl}^{7+}+\mathrm{D}$ show that the observed total electron cross section is fairly constant $\left(55 \times 10^{-16}\right)$ down to $50 \mathrm{eV} / \mathrm{u}$ where the cross section decreases, as might be expected from the low energy breakdown of the absorbing sphere model. The ion-atom merged-beams apparatus has also taken advantage of the recent metallic ion production capability of the ECR ion source and has begun to explore total electron capture cross sections for $\mathrm{Mo}^{4,5,7,9,11+}+\mathrm{D}$ at collision energies between 200 and $1000 \mathrm{eV} / \mathrm{u}$. Preliminary total cross sections for $\mathrm{Mo}^{4+}, \mathrm{Mo}^{5+}, \mathrm{Mo}^{7+}, \mathrm{Mo}^{9+}$, and $\mathrm{Mo}^{11+}$ are found to be $23.8,30.0,45.0,73.5$, and $91.9 \times 10^{-16} \mathrm{~cm}^{2}$, respectively, with an absolute 
error of $15 \%$. Electron capture cross sections for such low energy medium Z ions are needed for magnetic fusion edge and divertor plasma modeling.

\section{ACKNOWLEDGEMENTS}

This research was sponsored by the Division of Applied Plasma Physics, Office of Fusion Energy, and by the Division of Chemical Sciences, Office of Basic Energy Sciences of the U.S. Department of Energy, under contract N0. DE-AC05-84OR21400 with Martin Marietta

Energy Systems, Inc. M.P. acknowledges support from the "Nederlandse Organisatie voor Wetenschappelijk Onderzoek" (NWO). $\star$ Permanentaddress

Departmentof Physics, EastCarolinaUniversity, Greenville, N.C.27858 - 6739.

\section{DISCLAIMER}

This report was prepared as an account of work sponsored by an agency of the United States Government. Neither the United States Government nor any agency thereof, nor any of their employees, makes any warranty, express or implied, or assumes any legal liability or responsibility for the accuracy, completeness, or usefulness of any information, apparatus, product, or process disclosed, or represents that its use would not infringe privately owned rights. Reference herein to any specific commercial product, process, or service by trade name, trademark, manufacturer, or otherwise does not necessarily constitute or imply its endorsement, recommendation, or favoring by the United States Government or any agency thereof. The views and opinions of authors expressed herein do not necessarily state or reflect those of the United States Government or any agency thereof. 


\section{FIGURE CAPTIONS}

Figure I. Preliminary electron crossed-beams measurments of electron-impact ionization for $\mathrm{Mo}^{4+}$ ions. Error bars denote one sigma in reproducibility. Measurements have an absolute error on the order of $9 \%$.

Figure II. Absolute total cross sections for electron-impact excitation of the $4 \mathrm{~s}^{2}{ }^{1} \mathrm{~S} \longrightarrow$ $4 \mathrm{~s} 4 \mathrm{p}^{3} \mathrm{P}$ transition in $\mathrm{Kr}^{6+}$ as a function of the collision energy in the center-of-mass frame.

Figure III. Comparison of the measured and simulated scattered projectile intensity distribution on the $\mathrm{PSD}$ for $3.75 \mathrm{keV} / \mathrm{u} \mathrm{O}^{8}$ incident on $\mathrm{Au}(110)$ along the [110] direction at $1.8^{0}$ showing the characteristic "banana"-shaped angular scattering distributions, evident both in (a) the measurements and (b) the simulations.

Figure IV. Ion-atom merged-beams results (present results) compared with previous measurements and calculations. All vertical errorbars denote relative uncertainties estimated at the $90 \%$ confidence level. At $301 \mathrm{eV} / \mathrm{u}$ an additional vertical error bar denotes the absolute uncertainty at a $90 \%$ confidence level. Present calculations correspond to coupled-channel molecular orbital calculations [19]. 
[1] F. W. Meyer, Nucl. Instrum. Methods Phys. Res., Sect. B 9, 532 (1985).

[2] D. C. Gregory, F. W. Meyer, A. Muller, and P. Defrance, Phys. Rev. A 34, 3657 (1986).

[3] D. C. Gregory and M. E. Bannister, ORNL Report ORNL/TM-12729 (1994).

[4] M. E. Bannister, X. Q. Guo, and T. M. Kojima, Phys. Rev. A 49, 4676 (1994).

[5] E. W. Bell et al., Phys. Rev. A 4585 (1994).

[6] Phys. Rev. A 47, R9 (1993).

[7] M. S. Pindzola, D. R. Schultz, and D. C. Griffin, Phys. Rev. A 48, 4333 (1993).

[8] M. E. Bannister, X. Q. Guo, T. M. Kojima, and G. H. Dunn, Phys. Rev. Lett. 72, 3336 (1994).

[9] L. Folkerts, S. Schippers, D. M. Zehner, and F. W. Meyer, submitted to Phsysical Review Letters .

[10] H. Winter, C. Auth, R. Schuch, and E. Beebe, Phys. Rev. Lett. 71, 1939 (1994).

[11] J. Burgdorfer and F. W. Meyer, Phys. Rev. A 47, R20 (1993).

[12] F. Aumayr et al., Phys. Rev. Lett. 71, 1943 (1993).

[13] C. C. Havener et al., Phys. Rev. A 39, 1725 (1989).

[14] C. C. Havener, A. Muller, P. A. Z. van Emmichoven, and R. A. Phaneuf, submitted to Physical Review A.

[15] L. F. Errea, B. Herrero, L. Mendez, and A. Riera, J. Phys. B: At. Mol. Opt. Phys. 24, 2061 (1991).

[16] M. S. Huq, C. C. Havener, and R. A. Phaneuf, Phys. Rev. A 440, 1811.

[17] B. Zygelman et al., Phys. Rev. A 73, 3846 (1992). 
[18] N. Shimakura, M. Itoh, and M. Kimura, Phys. Rev. A 45, 267 (1992).

[19] L. Folkerts, C. C. Havener, N. Shimakura, and M. Kimura, submitted to Physical Review A . 


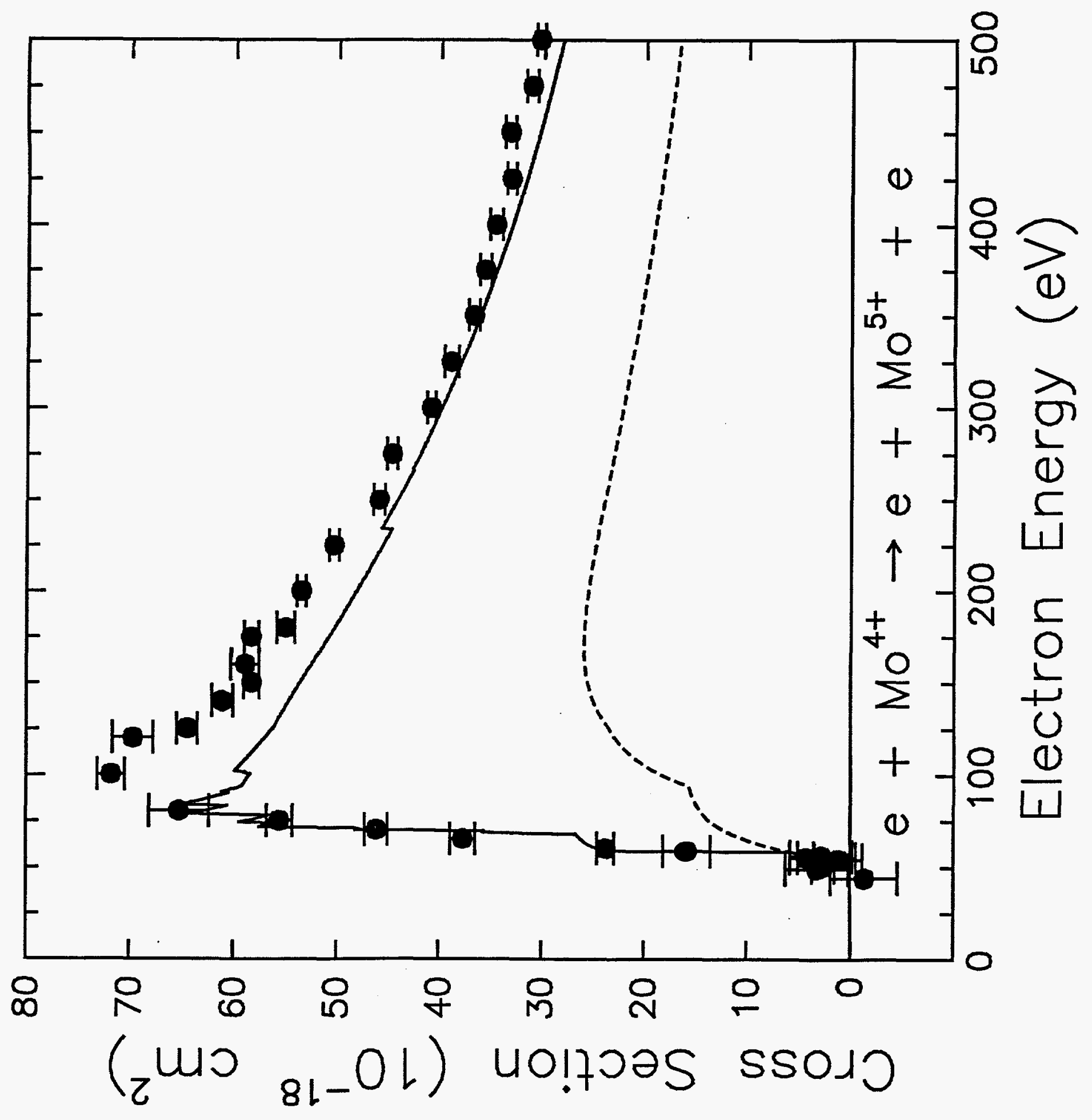

Fig. 1 


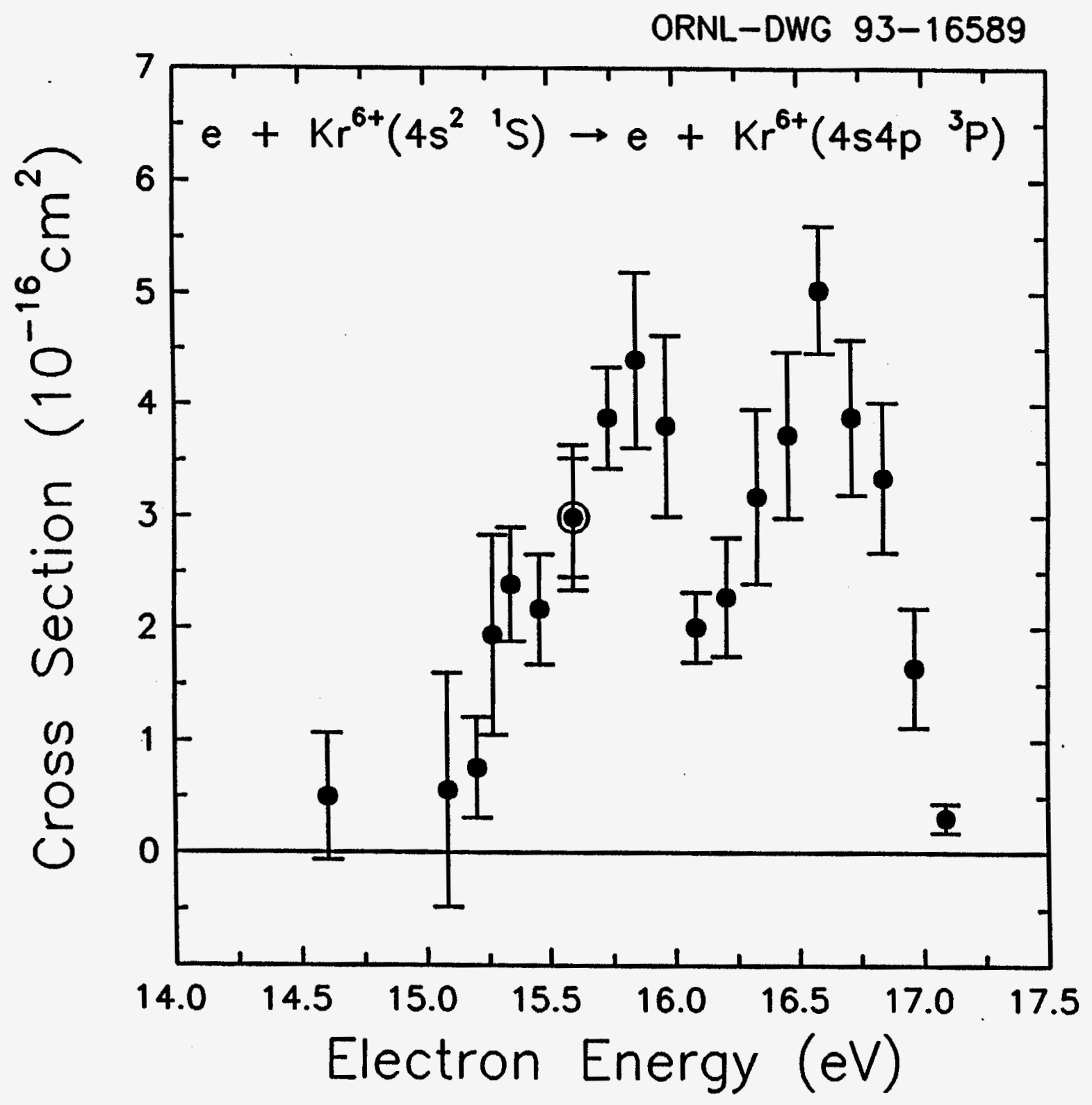



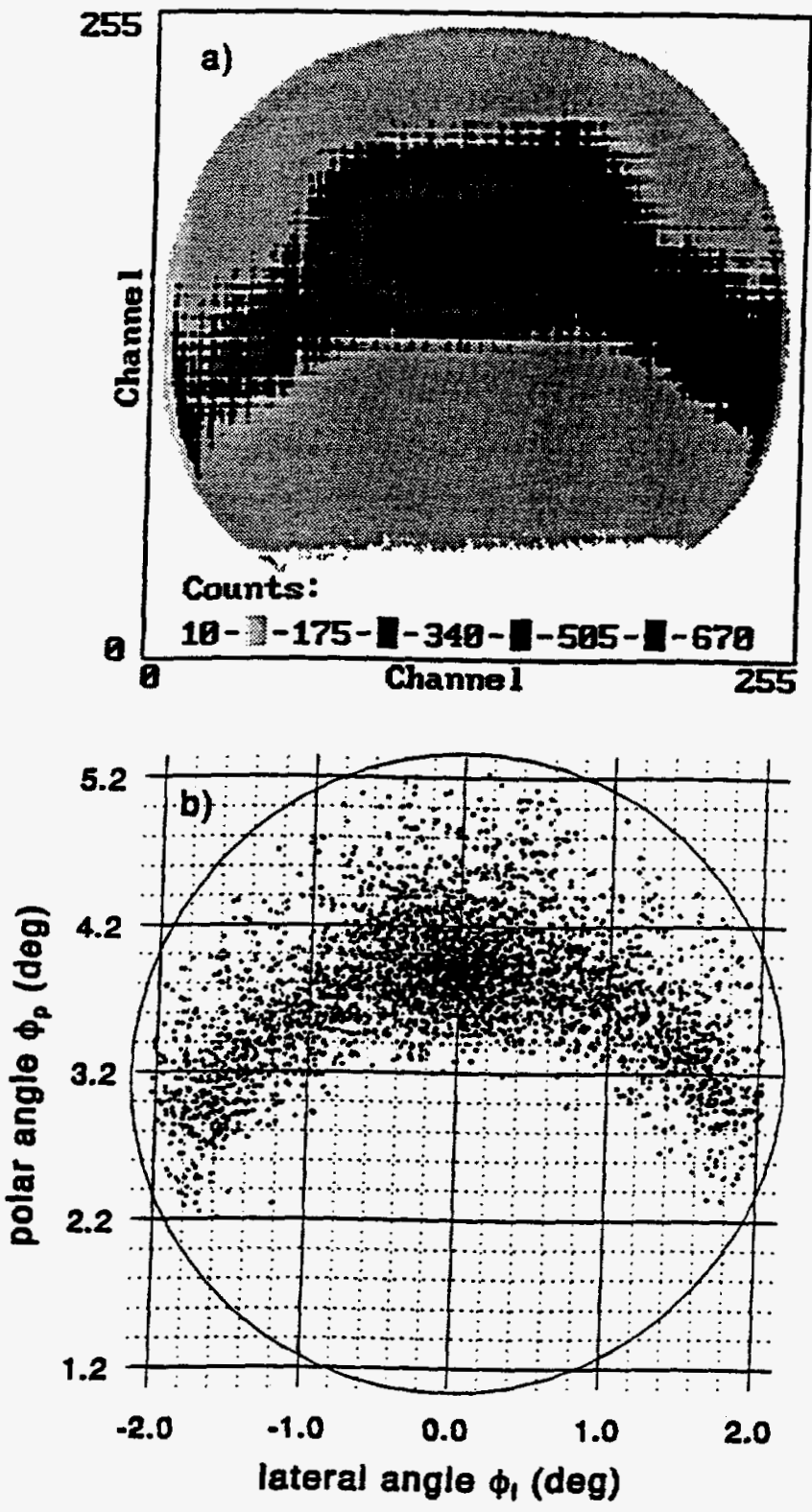


\section{$\mathrm{N}^{4+}+\mathrm{D}$}

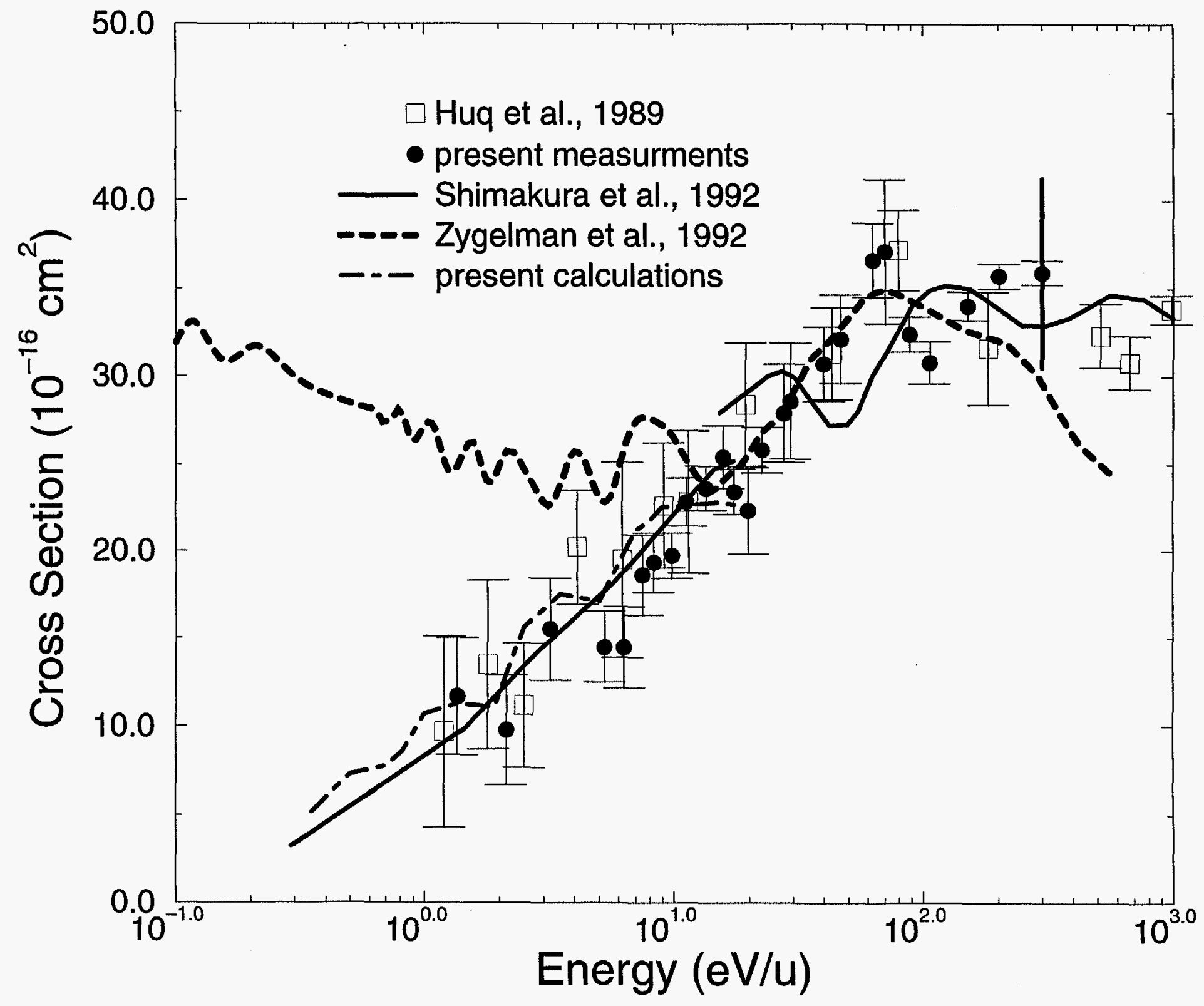

